\title{
Essay:
}

\section{Constructing a vignette for qualitative comparative family research}

by

Lennart Nygren

Professor, $\mathrm{PhD}$

University of Umeå, Sweden

Email: lennart.nygren@socw.umu.se

Siv Oltedal

Professor, PhD

University of Stavanger, Norway

E-mail: siv.oltedal@uis.no 


\section{Background}

In 2010, five European universities in the UK, Italy, Norway and Sweden were partners in a researcher exchange programme with Latin American partners in Argentina, Chile and Mexico. The programme, Understanding and Supporting Families with Complex Needs, was funded by the EU as a part of the FP 7 Marie Curie IRSES. The focus of this programme, which was finished 2014, was to exchange research and knowledge about social work with families by developing a large number of site-specific case studies.

As a part of the IRSES programme, the Norwegian and Swedish partners (the authors of this text) decided to develop a research approach that could help facilitate comparative research by providing a data collection method to be used during the researchers' secondments in other countries. This research approach is now established as an international network with the title: Social Work with Families (SWF). Researchers from approximately 20 universities have joined as partners in the SWF network. The partners have agreed to collect data from focus group interviews with social workers in their countries, and they have also agreed to use the same case vignette and instructions for the focus groups. The SWF network has arranged both webbased meetings and face-to-face meetings in relation to international conferences in order to share research findings and to discuss the implications of the research that has been achieved. Some of the research has also been presented at national and international conferences around the world, and an increasing number of research papers based on the SWF collaboration have been prepared and submitted to journals and other forms of publications. In this issue of the Journal of Comparative Social Work, there are examples of this (Haugen \& Klorudottir, 2015; Tembo \& Oltedal, 2015) and more is to come as soon as the researchers in the SWF network publish their analyses based on transcribed focus groups based on the same case vignette.

Since social work with families with complex needs is indeed also a complex issue, we were convinced that a qualitative approach was the most feasible. By combining focus group interviews with social workers with a case vignette, our ambition was to get comparable and aspect-rich data about the conditions to work with families with complex needs in the different settings. Simultaneously, since we were already engaged in other international networks, we invited colleagues from around the world to participate in this 
research, even if they were not part of the Europe-Latin America exchange project. This invitation was accepted by partners worldwide, and thus the research group includes Europe (Iceland, Finland, Lithuania, Russia, the UK, Denmark, Sweden, Norway and Spain), Australia, North America (Canada and the US), Latin America (Argentina, Chile, Mexico, Brazil and Cuba) and two African countries (Malawi and South Africa).

In this essay, it is our ambition to present the case vignette that by now is used in 14 different countries from around the world. Transcribed and translated (into English), focus group interviews from all these settings are available for analyses to the partners in the SWF network, and they also have access to the original vignette in several languages (English, Swedish, Norwegian, Spanish, etc.). Besides presenting the vignette and therefore making it possible to refer the readers of future publications to it, the aim of this essay is to discuss some of the particular challenges and profits from using case vignettes in qualitative comparative research (Nygren \& Oltedal, 2014).

\section{Vignettes in qualitative research}

Vignettes are used in both quantitative (Smithson, 2000) and qualitative research, and a general impression is that the use of vignettes in qualitative research is increasingly common (Wilks, 2004). The development over the past three-four decades has been tremendous. Vignettes were used in anthropology and psychology in the early 1950s, and are often used in disciplines that relate to specific professions such as health-related professions and social work (Kriz \& Skivenes, 2013a; Smithson, 2000). Vignettes are sometimes used in research as a part of group interviews with patients, clients, youth, etc., but have perhaps more and more been recognized as a powerful instrument to investigate professional's perceptions, beliefs and attitudes in relation to the complex work tasks, to help investigate emotions that emerge in difficult situations and to explore both professional decision-making (Kriz \& Skivenes, 2013a) and judgements (Smithson, 2000). There are also examples in which researchers attempt to capture contextual conditions for professional work since barriers and facilitating structures can become visible in relation to each case presented in a vignette. Yet another application of vignettes is in longitudinal research, where group reasoning in relation to a situation changes due to different external factors such as treatment, education, etc. (Jenkins, Bloor, Fischer, Berney, \& Neale, 2010). A specific and challenging way to use case 
vignettes is to be found in qualitative comparative research, such as what we are doing in the SWF project. A qualitative approach was regarded as necessary due to the complexity of the phenomenon that was the focus of the research. In comparative research, different statements of social workers' actions and the rationale for these are intertwined with the institutional and cultural contexts in ways that can be visualized in focus group discussions. In this specific project, we ask practitioners/professionals to discuss three problematic situations in a social work process covering a six-year timespan, presented as vignettes and additional questions in a focus group setting. Even if studies of this kind are not so common, there have been attempts in social work research to develop such designs, e.g. in the field of child welfare (Jegerby \& Soydan, 2002; Khoo, Hyvonen, \& Nygren, 2003; Kriz \& Skivenes, 2013a, 2013b). In comparison with previous approaches, we have tried to increase the contextual content more explicitly by asking about social workers' views on "family" in general, as well as about the welfare mix they are situated within.

\section{The vignette - considerations in the design phase}

The constructors of case vignettes need to take many aspects into account. Here, we will describe some of them briefly in order to show some of the considerations that have been at stake in the making of the SWF vignette.

\section{Research focus}

An important consideration is - naturally - related to the focus of the research questions. If we are interested in professional judgements and what they are based on and restricted by, we need to make space and invent triggering details for such discussions through the vignette. Additionally, how the action that social workers may take form is dependent on organizational, judicial or other structural contexts, so the instructions to the focus group is also to consider such external conditions in their discussion. This creates a dilemma, where on the one hand we need to achieve a balance between making social workers talk about which actions they consider in relation to the case, and on the other, how these actions are conditioned by different contextual restrictions and resources. 


\section{The cultural setting}

The issue of cultural context was a struggle in constructing the vignette. Since the idea here was to create a case that could be recognizable for social workers in many different global contexts, the vignette had to be communicated in several rounds with members of the SWF network. Would this case be plausible in Sweden, Malawi, Australia and México, just to mention a few countries in the SWF network? In the process of constructing the vignette, we have had reactions from different partners about the relevance of both concepts and some of the details in the situations presented in the case.

\section{Different welfare provider systems, judicial and professional contexts}

In different welfare states, there are differing constructions of social problems, and hence also the solutions that are offered. A problem that is considered as severe and requires interventions from the state in one setting may be considered less serious in another setting. Not all solutions involve social workers in all countries, but do involve other professionals (or are seen as a family issue). For example, we can see this in how different countries have built up foster care, while others have chosen to build institutions. The idea of permanency for the child is not equally strong in different countries. Even if such differences are interesting findings from comparative analyses of the material, they also set the focus on the need to not be too specific in the case story about different measures since they may not function in all contexts.

\section{Icebreaker}

It is necessary to consider the functions of the vignette in the focus group interview. The vignette can function as an icebreaker, i.e. to make people start talking about a specific topic. It has to be easy to grasp, and it has to balance between not being too trivial and not being too extreme. The aim was to conduct the discussion in such a way that it would create a difference that makes a difference (Bateson, 1972). Ideally, it should trigger the group to start their discussion, but it should not lead them into a discussion about how realistic the case is, whether it is extremely unusual, etc. (Skytte, 2002). In our case, we start the vignette by describing a pregnant 14-year-old girl who lives in a family where there is domestic violence taking place. This situation is complex and difficult, but also not unusual in most settings. 
The structure of the vignette

A choice had to be made regarding whether the vignette was to be a "snapshot" (i.e. a static situation) or representing a process with different stages (Jenkins et al., 2010; Krueger \& Casey, 2000). It was our thought that by successively introducing new phases, it was possible to initiate more discussions about both the context and to trigger more talk about norms and values. But new phases can be of different types; it is quite common to let the phases represent an escalating problem, moving from a quite everyday situation to a more and more intervention-demanding situation (Khoo et al., 2003). In our case we have partly followed this rationale, but it is more adequate to say that we have identified the developmental phases of a young person. It has to do with age, maturity, social environment and intergenerational relationships that change over time, and indicates that we are not targeting a specific professional. Instead, there may be several service providers and professionals that the focus group identifies, in addition to variable roles for the family members or the extended family depending on the context. That is also why the phases in the vignette do not entirely follow the idea of escalating problems, but rather that the last phase represents a more mature individual with relatively less serious (and different) problems than in the preceding phases.

\section{The question of language}

A parallel aspect of this is the translation of the vignette to other languages such as Spanish, Russian, Swedish, Finnish, Lithuanian and so on, though not all words end up with the identical meaning in this process. This of course is also a problem in relation to the translation of the transcripts from the focus groups and not entirely solvable, even if we intend to use highly qualified translators, and depending on access to resources, we might also use back-translation procedures.

\section{Considering the analytical phase}

The focus group discussions generate a rich data in terms of moral statements, professional judgements and knowledge about the influence from contextual factors on social work practice (Krueger \& Casey, 2000). Some of the topics generate facts and temporarily ordered descriptions of procedures, whereas other topics tend to trigger storytelling and produce narratives. This opens up for many ways to analyse data, since we can have a focus on moral themes, discourses, group interactions, meaning making, contextual analysis and descriptions, just to mention some possible analytical entrances 
(Smithson, 2000). We think that there is no unique way to analyse the data we get, as it always depends on the research question, and that the balance between open probes in relation to the situations of the vignette and more specific requests to the focus group, will be the optimal strategy to get both aspect-rich data and enough structured data for making comparative analyses. Also, we need to consider what type of outcome we expect from the analysis, as focus group data (and qualitative data in general) are not feasible for empirical generalizations, but rather for theoretical generalizations (Sim, 2001). According to how it is constructed, the vignette presented here is aiming at producing data for the purpose of theorizing social work actions in different welfare systems, and thus has a generalizing ambition in the theoretical sense.

\section{The vignette}

In this section, we present the English version of the vignette in order to give readers a possibility to study the construction in terms of phases, but also to see the probing questions that were asked in the focus groups. These questions are also important in the creation of the research context: What aspects did we expect the focus group participants to focus on? As we see in the focus group instructions, we have attempted to address the issue mentioned in the method literature about whether capturing a role performance or whether we capture the actual action focus group members would apply in different situations. Focus group data does not represent real action, and we cannot be sure whether the members of the group would act according to what they say in these discussions, as well as a risk that we may get socially desirable answers (Hughes \& Huby, 2004). In some cases, focus group members take the role of the characters in the vignette, and their reasoning is more about what the (partially imagined) character would do than what they themselves would do in a real situation. We think that by asking the focus group about their recommendations to an "ideal type" social worker in the situation, we will capture general values and judgements that are typical of the setting where the focus group is carried out (O'Dell, Crafter, Abreu, \& Cline, 2012).

The vignette and the focus group instructions used in the SWF project are presented below: 
Vignette "Social Work with Families" revised edition: 08.11.2010, revised after proofreading before publication 20.05.2015

\section{Task 1}

The focus group members present to a foreigner how they understand the concept of "family" in their country, and how they usually work with families in social work, and in particular in child welfare work.

\section{Situation 1}

Maria, a 14-year-old girl comes to the school counsellor. Maria tells her that she is six months pregnant, but does not think that anybody knows about her pregnancy. She thinks it will be best for her child if Maria's mother takes care of the child until Maria turns 18 and becomes an adult. She asks if the counsellor can talk to her mother about this.

During their talks Maria tells the counsellor that she is her mother's only child. Her mother and her father come from the countryside, and Maria's grandmother and grandfather live in her neighbourhood. Maria's parents are 30 years (mother) and 32 years (father), and rarely return to the rural area they come from, and apart from a positive relationship with Maria's grandparents, they are isolated from other family members. Maria's pregnancy is the result of a short relationship she had with a young man, Peter (16 years), who lives in her neighbourhood. Although she still sees Peter around the neighbourhood, they are no longer in a relationship. Her relationship with Peter was her first sexual relationship, and she is now ashamed that she had become pregnant.

Maria also tells the counsellor that both she and her mother are afraid of her father when he gets angry. When Maria was five years old, her mother came running into the bathroom where Maria was, and told her to close the door so that her father could not come into the bathroom. Her mother was bleeding from wounds in her face, which were caused by her husband, who had beaten her. He also occasionally beat Maria, 
which happened the last time two years ago when she came home an hour late after visiting a boy her father incorrectly believed to be her boyfriend.

The counsellor says she is cooperating with other professionals. Maria accepts that the counsellor may have talks later the same week with a group of social workers about her situation, and the two agree to have a new talk about a week later.

\section{Focus group's Task 2}

What advice will you give the counsellor before the next talk with Maria, and what further initiatives will you suggest that the counsellor should take? What other actions will your group recommend? (Who will do what with whom?)

\section{Situation 2}

Maria is now 16 years old, and has dropped out of school. Maria had considerable trouble raising her daughter, Penny (2 years), and agreed for her to be taken into foster care. Maria is also unable to live with her parents due to the violence between her parents, which has become much worse over the last couple of years. The local child protection services has decided that Maria is to be moved into supported housing in the community, and a s social worker at the local child protection service is now going to inform Maria about this decision.

\section{Focus group's Task 3}

Discuss what advice you would give to the social worker before he/she meets Maria about how to help her. And what further initiatives would you suggest in this case? Moreover, what is the role of Maria's family in this?

\section{Situation 3}

Maria has turned 18 years old and reached a lawful age. She comes to the local public welfare service centre to demonstrate that she has a job and emotional stability, and she says that she wants her daughter to live with her. She tells that she and her mother have lately been to a meeting with a public welfare service centre psychologist, who 
is worried about Maria's daughter because she is hitting other children when they are playing. Maria has only seen the child approximately one weekend every month during the two last years. The child has had several changes in foster carers, and Maria believes that she would be able to provide Penny with more stability than she has experienced in the foster system.

\section{Focus group's Task 4}

What advice would you give to the social worker at the local public welfare service centre concerning his/her talk with Maria on these topics, and what further initiatives should be taken in this case? What is the best outcome for Maria and her family in the long run?

\section{Focus group's Task 5}

Reflect on the case and its different stages, and discuss what this can tell about how social workers can cooperate with the family in a local context (as in this case with Maria). Discuss how this case more generally can tell something about the "welfare mix" in your country, which means the relationship among NGOs, civil society, family and state as partners in a cooperation to extend help in situations like the one with Maria.

Background information about the participants in the focus group interview has also been collected. This is about age, gender, education and in addition, the participants could write briefly about their professional work history in a self-reporting scheme.

\section{Concluding remarks}

Thus far, we have seen both advantages and some deficiencies with the use of this vignette. We recognize most of these in previous publications about the vignette method, some of which we have referred to in this paper. Advantages we have experienced are:

i) That we will achieve a reasonable level in the standardization of data collection, which is necessary for comparative research.

ii) In combination with the focus group design, the use of the vignette has proven to give access to good enough data - data that tells us how social workers in 
different global contexts construct their conception of family, and how they approach the complex needs that may appear in child welfare work. In this way, we think that we can represent the ethos of the profession, and that we are able to show how this is conditioned by different national and cultural contexts.

iii) By using vignettes, we have avoided the problem of social workers talking about sensitive and difficult judgements in real life in order to better understand their more "in-principal" idea of complex problems and how they are to be dealt with. This means that it is easier to talk quite concretely about the work and the conditions for it (thanks to the details of the vignette). It is also a way to avoid an ethical research dilemma since in this case focus group members do not need to use examples from their own practice in their discussions.

iv) The comparative potential is high, since we will collect many focus group interviews through the network. Some of these may be clustered together so we can, e.g. compare different welfare regimes besides comparing individual countries.

v) Both because of the vignette construction in itself and in particular in relation to the last task (task 5), we get contextual data that goes beyond what we usually manage to achieve in group interviews. Contextual data is crucial for making sense of social workers' perceptions, beliefs, judgements and suggested actions.

We have identified that there are some possible weaknesses with the design of the SWF project. As with all vignette studies, there is the issue of validity, i.e. whether the suggested actions from the focus group would also be the "real" action in real situations, as there is no easy way around this problem. On the other hand, it is reasonable to believe that data from vignette studies represent collective perceptions of certain problems, and also both the values and the impact of the social political context on their actions in the real world. (Hughes \& Huby, 2004).

The cultural bias in the construction of a vignette is something that we attempted to overcome through intensive communication within the network. Nevertheless, when focus groups were implemented, it was discovered at times that the family relationships 
that are described may not be applicable in all cultures, at least not in the same way. Moreover, the first words in the vignette include "school counsellor", which is a one way to label social workers working in schools. This sub-profession in social work does not exist in all contexts, and the focus group mediator had to adapt to the group by suggesting alternatives.

We have already touched upon the problems with the translation of both the vignette and the interviews, and the response to this problem is to find a good translator, as well as some members of the network being bilingual (are fluent in two languages). We have also discovered that the mode of interviewing varies, even if we have tried to standardize the probing questions. This can have some effect in particular on the data we get about the contexts that becomes richer in some settings and poorer in others. To date, we have planned for at least two focus groups per SWF member. This seems to work out fine in most settings, but since groups are composed a bit differently in different settings it is very important to get good information about the participants. It would possibly be ideal to increase the number of focus groups in each setting in order to avoid bias from groups that are not entirely composed in the best manner. Some groups may also be affected by destructive group processes so that the data they generate will be incomplete and/or biased. There are one or two examples in which this calls for adding a third group interview to the material.

To summarize:

- Focus groups with vignettes provide understandings about how families and the role of social workers in relation to complex needs are understood in different contexts.

- Findings from analyses have the potential to generate knowledge about their contextual dependency in social work (on different theoretical levels).

- Variations in focus groups (participants, professional positions, work context, size, etc.) and the details of how case vignettes are constructed (realism, balance between vagueness and concreteness, etc.) are critical elements for the possibility to contextualize qualitative comparisons. 


\section{References}

Bateson, G. (1972). Steps to an ecology of mind. New York: Ballantine Books.

Haugen, A., \& Klorudottir, S. Y. (2015). The involvement of family in child protection cases in Iceland. In: Journal of Comparative Social Work, Issue 1.

Hughes, R., \& Huby, M. (2004). The construction and interpretation of vignettes in social research. Social Work and Social Sciences Review, 11(1), 36-51.

Jegerby, U., \& Soydan, H. (2002). Assessment processes in social work practice when children are at risk - a comparative, cross-national vignette study. Journal of Social Work Research and Practice, 3(2), 127-144.

Jenkins, N., Bloor, M., Fischer, J., Berney, L., \& Neale, J. (2010). Putting it in context: The use of vignettes in qualitative interviewing. Qualitative Research, 10(2), 175-198.

Khoo, E. G., Hyvönen, U., \& Nygren, L. (2003). Gatekeeping in Child Welfare: A Comparative Study of Intake Decision-making by Social Workers in Canada and Sweden. Child Welfare, 82(5), 507-525.

Kriz, K., \& Skivenes, M. (2013a). Risk assessment in different welfare states: A comparative case vignette study. Children \& Youth Services Review, 35, 1862-1870.

Kriz, K., \& Skivenes, M. (2013b). Systemic differences in views on risk: A comparative case vignette study of risk assessment in England, Norway and the United States (California). Children \& Youth Services Review, 35, 1862-1870.

Krueger, R. A., \& Casey, M. A. (2000). Focus groups: A practical guide for applied research. Thousand Oaks: Sage Publications.

Nygren, L., \& Oltedal, S. (2014). Social workers' understanding of 'family' in child welfare work - an international research approach. In S. Hessle (Ed.), Social work - social development Vol III: Global social transformation and social action: The role of social workers (Vol. III, pp. 123-127). Ashgate: Aldershot.

O'Dell, L., Crafter, S., Abreu, G. de, \& Cline, T. (2012). The problem of interpretation in vignette methodology in research with young people. Qualitative Research, 12(6), 702-714.

Sim, J. (2001). Collection and analysing qualitative data: Issues raised by the focus group. Journal of Advanced Nursing, 28(2), 345-352.

Skytte, M. (2002). Placing ethnic minority children - Studied by using vignettes. Lund: Lund University, School of Social Work.

Smithson, J. (2000). Using and analysing focus groups: Limitations and possibilities. Social Reserach Methodology, 3(2), 103-119. 
Journal of Comparative Social Work 2015/1

Tembo, M. J., \& Oltedal, S. (2015). Social Work and Families in child welfare in Malawi: Social Workers Considerations when Placing a Child outside Home. In: Journal of Comparative Social Work, Issue 1. 